\title{
A classically conditionable skeletal response can be acquired with a discriminated punishment contingency*
}

\author{
WILLIAM F. PROKASY, CRAIG G. CLARK, WILLIAM C. WILLIAMS \\ and CHARLES W. SPURR \\ University of Utah, Salt Lake City, Utah 84112
}

\begin{abstract}
Human Ss were exposed to a discriminated punishment contingency with the aversive stimulus being an air puff to the cornea. In most Ss there was an increase in response probability (an eyelid reflex) across trials and an application of the two-phase model showed that the increases, though not great, were reliable. An analysis of the estimated parameter values showed that for only 5 of the 26 Ss did the pattern of parameter values conform to what would be expected on the basis of either two-factor or relative reinforcement theory. The results were, however, consistent with what might have been expected from giving Ss a low ratio intermittent reinforcement schedule in a more traditional classical conditioning arrangement.
\end{abstract}

Through the use of the two-phase model Prokasy (in press) has shown that two-factor theory has difficulty accounting for the acquisition of a discriminated avoidance response (CR), in this case conditioned paw reflexes in dogs and cats. The basic argument is that the net effect of a trial on which a CR occurs and the UCS is avoided (i.e., a CS-CR-UCS trial) is to decrease response probability, and the net effect of a trial on which a CR fails to occur (i.e., a CS- $\overline{C R}-U C S$ trial) is to increase response probability. The latter directly follows from the acquisition of fear to the CS, the result of CS-UCS pairing. The CS-CR-UCS trial has two consequences. One is $\mathrm{CR}$ reinforcement via fear reduction. The other is a reduction in the fear itself. These consequences have opposite effects on the strength of the tendency to respond. The former tends to increase, the latter to decrease, response strength. At some point the net impact of these two consequences must be a reduction in response strength, for it is the repeated occurrence of the CR over successive trials at asymptote which is presumed to initiate CR extinction. Prokasy (in press) made the specific assumption that as applied directly to response probability the limit of an operator applied to CS-CR- $\overline{U C S}$ trials was lower than that of an operator applied on CS- $\overline{C R}$-UCS trials. The results of the study showed quite clearly, contrary to theoretical expectation, that the operator limits were in the reverse order.

While it is reasonable to argue that with extended

*This research was supported by NSF Grant GB-30527X to the senior author. training the CS-CR-UCS trial results in a net decrement in response strength, it isn't logically necessary that the effect is routinely a change in response strength toward the lower of two operator limits. For example, Rescorla and Solomon (1967) illustrate a condition in which response strength below asymptote at the end of training nonetheless continues to increase with the onset of the extinction operations.

The purpose of this study is to examine the implications of two-factor theory in a discriminated punishment situation (Grant, 1964). The theoretical predictions for this situation are clearly independent of the specific mapping assumption made to test the theory in a discriminated avoidance setting. In discriminated punishment the two trial outcomes are CS-CR-UCS and CS- $\overline{C R} \cdot \overline{\mathrm{UCS}}$. Thus, S's failure to make the $\overline{\mathrm{CR}}$ is what avoids the aversive UCS. Moreover, to the extent that fear is acquired to the CS, the occurrence of $\mathrm{CR}$ is reinforced and also results in fear reduction. Not only should CR conditioning not occur, it would be expected that overall performance will decrease to a level below the operant rate.

It is noted that Perkins's relative reinforcement theory (Perkins, 1968) and Spence's drive theory (Spence, $1956,1960)$ also yield rather precise, though differing, predictions for discriminated punishment. The Perkins theory would hold that the relative attractiveness of CS- $\overline{C R}-\overline{U C S}$ is greater than that of CS-CR-UCS and that, therefore, the organism would reduce CR rate over trials. Spence's theory predicts a counter intuitive outcome. Habit strength is acquired solely as a function of CS-UCS 
pairings independent of whether or not a CR occurs. Given an initial response rate above 0.0 and an aversive UCS, CRs should be acquired through the occasional UCSs. For those Ss for whom initial response rate is low, a high performance level would be unlikely since, according to the theory, a CS- $\overline{\mathrm{CR}} \cdot \overline{\mathrm{UCS}}$ trial generates inhibition, with the consequent lowering of response strength.

The discriminated punishment data will be analyzed with the use of the two-phase model (Prokasy, 1972; 1973; in press; Prokasy, Williams, Lee, \& Kumpfer, 1974). The model is two-phase in that during Phase $1, \mathrm{~S}$ responds at an initial operant rate, $\mathrm{P}_{\mathrm{o}}$. On Trial $\mathrm{K}$ a switch is made to Phase 2 during which changes in CR likelihood takes place. Response probability on Trial I, $P_{i}$, is expressed:

$$
\begin{aligned}
\mathrm{P}_{\mathrm{i}}= & \mathrm{P}_{\mathrm{o}}, \mathrm{i}=1, \mathrm{~K} \\
\mathrm{P}_{\mathrm{i}}= & \mathrm{P}_{\mathrm{i}-1}+\theta_{1}\left(\lambda_{1}-\mathrm{P}_{\mathrm{i}-1}\right) \\
& \mathrm{i}=\mathrm{K}+1, \mathrm{~N} \text {, given a CR on Trial } \mathrm{i}-1 \\
\mathrm{P}_{\mathrm{i}}= & \mathrm{P}_{\mathrm{i}-1-1}+\theta_{2}\left(\lambda_{2}-\mathrm{P}_{\mathrm{i}-1}\right) \\
& \mathrm{i}=\mathrm{K}+1, \mathrm{~N} \text {, given CK } \text { on Trial } \mathrm{i}-1
\end{aligned}
$$

where $\theta_{1}$ and $\theta_{2}$ are rate-change parameters and $\lambda_{1}$ and $\lambda_{2}$ are limits. Note that the first operator applies to CS-CR-UCS trials and the second to CS- $\overline{\mathrm{CR}}-\overline{\mathrm{UCS}}$ trials.

\section{METHOD}

\section{Apparatus}

Eyelic nio'tenents were converted to voltage changes by means of a wire attached to S's right eyelid and to the shaft of a microtorque potentiometer (see Prokasy \& Whaley, 1961, for further details). Responses were amplified by a Beckman 482AM8 power amplifier, which provided a $\pm 1 \mathrm{Vdc}$ RMS output to the A/D converter of a PDP12A computer.

Ss were seated in one of two separate $1.8 \times 1.8 \mathrm{~m}$ cubicles. A stimulus panel, consisting of lights behind an $8 \times 55 \mathrm{~cm}$ strip of plastic, was located approximately $1 \mathrm{~m}$ in front of Ss at eye level.

The CS was a light rated at $2 \mathrm{~W}$, illuminated for $750 \mathrm{msec}$. The UCS was a 50-msec puff of nitrogen, delivered to the cornea of S's right eye at CS offset. The intensity of the UCS was sufficient to support a $175-\mathrm{mm}$ column of mercury.

A DEC PDP12A computer programmed the ISIs (interstimulus intervals), ITIs (intertrial intervals), CSs and UCSs. The mean ITI was $7.5 \mathrm{sec}$, with 6-, 7-, 8-, and 9-sec ITIs sequenced unsystematically. The ISI was $765 \mathrm{msec}$.

\section{Subjects}

The Ss were 31 male and female student volunteers from introductory psychology classes at the University of Utah. Five Ss were lost due to apparatus failure or E error.

\section{CR Definition}

CRs were scored by the computer, employing amplitude and slope criteria. Only those responses occurring from $150 \mathrm{msec}$ after CS onset until CS offset were counted. The program for CR detection has an error rate of approximately .131\% (see Clark, 1974).

\section{Procedure}

Ss were run in parallel whenever possible. Brief tape recorded instructions explained the stimuli to be employed and requested that Ss sit quietly and let their reactions take care of themselves. All Ss received the same sequence of 55 adaptation trials, consisting of a random sequence of 40 CSs and 15 UCSs. On the subsequent 320 trials, Ss received the UCS only on those on which a response occurred. Each experimental session lasted $47 \mathrm{~min}$.

\section{RESULTS}

Parameters were estimated separately for each S with the use of the computer subroutine STEPIT (Chandler, 1969). Estimates were obtained under four different assumptions:

$$
\begin{array}{ll}
\text { A } & \theta_{1}=\theta_{2}, \lambda_{1}=\lambda_{2} \\
\text { B } & \theta_{1} \neq \theta_{2}, \lambda_{1}=\lambda_{2} \\
\text { C } & \theta_{1}=\theta_{2}, \lambda_{1} \neq \lambda_{2} \\
\text { D } & \theta_{1} \neq \theta_{2}, \lambda_{1} \neq \lambda_{2}
\end{array}
$$

Using a likelihood ratio criterion (see Prokasy, 1973, for details), each $\mathrm{S}$ was classified according to which of the above assumptions was sufficient to describe the conditioning protocol.

Table 1 provides the best-fit parameter estimates for each S, together with an indication of which of the four assumptions applied to each. The obvious fact is that performance did change. ${ }^{1}$ That is, $\mathrm{K}$ was less than 320 for all Ss, indicating that two phases reliably exist. Twelve of the 26 Ss can be described with a single operator. Of these, 8 had $\lambda_{1}>P_{o}$. Of the 14 Ss requiring two operators, 10 had $\lambda_{1}>P_{0}, 7$ had $\lambda_{2}>P_{0}$ and 11 had $\lambda_{1}>\lambda_{2}$.

Average response probability over trials did not increase greatly. Beginning with $\mathrm{P}_{\mathrm{o}}$, and partitioning acquisition into 8 blocks of 40 trials each, response probability across blocks was: $.200, .208, .237, .274$, $.258, .288, .291, .282$, and .289 . Of the 26 Ss 10 had a response probability on the final block of 80 trials that was lower than $\mathrm{P}_{\mathrm{o}}$.

\section{DISCUSSION}

Though not characteristic of all Ss, it is evident that a discriminated punishment contingency, when applied to skeletal responses which are classically conditionable, does result in acquisition of the punished CR. For 21 of the 26 Ss at least one of the two operator limits was above $\mathrm{P}_{\mathrm{O}}$. In general, then, neither two-factor theory (Rescorla \& Solomon, 1967) nor relative reinforcement theory (Perkins, 1968) can account for the data.

At a gross level, Spence's theory (Spence, 1956; 1960) accounts for the data, since it predicts $C R$ acquisition in a discriminated punishment situation. Moreover, because $P_{0}$ is relatively low, the frequency of application of the $\overline{\mathrm{CR}}$ operator is such as to assure relatively low CR rates. However, there are two 
Table 1

Estimates of Parameters for Individual Subjects*

\begin{tabular}{|c|c|c|c|c|c|c|c|}
\hline $\mathrm{S}$ & Assumption & $\mathrm{P}_{\mathrm{O}}$ & $\mathrm{K}$ & $\theta_{1}$ & $\lambda_{1}$ & $\theta_{2}$ & $\lambda_{2}$ \\
\hline 8 & A & .073 & 245 & 1.000 & .106 & 1.000 & .106 \\
\hline 9 & A & .366 & 4 & 1.000 & .278 & 1.000 & .278 \\
\hline 14 & A & .244 & 123 & 1.000 & .122 & 1.000 & .122 \\
\hline 16 & A & .098 & 82 & 1.000 & .188 & 1.000 & .188 \\
\hline 18 & A & .073 & 307 & .680 & .147 & .680 & .147 \\
\hline 20 & A & .634 & 2 & 1.000 & .984 & 1.000 & .984 \\
\hline 21 & A & .244 & 73 & .802 & .340 & .802 & .340 \\
\hline 24 & A & .073 & 160 & .662 & .157 & .662 & .157 \\
\hline 28 & A & .195 & 142 & 1.000 & .360 & 1.000 & .360 \\
\hline 29 & A & .098 & 14 & 1.000 & .013 & 1.000 & .013 \\
\hline 31 & A & .415 & 2 & 1.000 & .166 & 1.000 & .166 \\
\hline 32 & A & .049 & 3 & .085 & .285 & .085 & .285 \\
\hline 10 & $\mathrm{C}$ & .220 & 2 & .425 & .897 & .425 & .063 \\
\hline 11 & $\mathrm{C}$ & .244 & 14 & .465 & .776 & .465 & .060 \\
\hline 13 & C & .390 & 52 & .564 & .731 & .564 & .244 \\
\hline 15 & C & .122 & 2 & .143 & .744 & .143 & .045 \\
\hline 19 & C & .268 & 15 & .220 & .920 & .220 & .401 \\
\hline 25 & C & .049 & 39 & .256 & .462 & .256 & .066 \\
\hline 26 & C. & .122 & 56 & .582 & .431 & .582 & .065 \\
\hline 27 & C & .098 & 143 & 1.000 & .097 & 1.000 & .487 \\
\hline 30 & C & .390 & 14 & .702 & .345 & .702 & .101 \\
\hline 33 & C & .341 & 4 & .759 & .631 & .750 & .218 \\
\hline 12 & D & .122 & 30 & .132 & .942 & .602 & .205 \\
\hline 17 & D & .171 & 106 & .821 & .917 & .381 & .232 \\
\hline 22 & D & .146 & 55 & 1.000 & .003 & .003 & 1.000 \\
\hline 23 & D & .220 & 88 & .354 & .000 & .018 & 1.000 \\
\hline
\end{tabular}

*Note that identical values are entered under $\theta_{1}$ and $\theta_{2}$ and under $\lambda_{1}$ and $\lambda_{2}$ when the assumption category may assume either a single $\theta$ or single $\lambda$.

difficulties with the theory. First, since inhibition is generated with $\overline{\mathrm{UCS}}$, and since $\overline{\mathrm{UCS}}$ is correlated with $\overline{\mathrm{CR}}$, all $S$ s should have required two operators with $\lambda_{1}>\lambda_{2}$. Second, while those Ss who required two operators did (with three exceptions) conform to the expectation that $\lambda_{1}>\lambda_{2}$, this pattern is also characteristic of two-operator Ss exposed to classical conditioning training in which CS-UCS pairing occurs on every trial. It seems likely, therefore, that the difference in limits is attributable to whether or not a CR occurs and not to whether or not a UCS is administered.

It is not argued here that the general result of a discriminated punishment contingency would be to increase the frequency of the punished CR. To the contrary, there is evidence with other response systems (e.g., Church, 1969, Pp. 142-145) that the punished response decreases in frequency. It is entirely possible, though, that skeletal responses which can be conditioned with classical conditioning operations constitute a response category with properties different from that of responses not classically conditionable. Consistent with this possibility are two outcomes reported by Gormezano and Coleman (1973): (1) as response-contingent aversive UCS intensity increased, overall performance level increased, and (2) omission training with an appetitive UCS resulted in CR acquisition. Neither of these results, as the authors noted, are consistent with law-of-effect theories, although both are consistent with drive theories.

\section{REFERENCES}

Chandler, J. P. STEPIT: finds local minima of a smooth function of several parameters. (CPA 312) Behavioral Science, 1969, 14, 81-82.

Church, R. M. Response suppression. In B. A. Campbell and R. M. Church (Eds.), Punishment and aversive behavior. New York: Appleton-Century-Crofts, 1969.

Clark, C. G. Manipulation of CR-contingent UCS intensity in human eyelid conditioning: A two-phase model analysis. Unpublished M.S. thesis, University of Utah, 1974.

Gormezano, I., \& Coleman, S. R. The law of effect and CR contingent modification of the UCS. Conditional Reflex, $1973,8,41-56$

Grant, D. A. Classical and operant conditioning. In A. W. Melton (Ed.), Categories of human learning. New York: Academic Press, 1964.

Perkins, C. C., Jr. An analysis of the concept of reinforcement. Psychological R eview, 1968, 75, 155-172.

Prokasy, W. F. Developments with the two-phase model applied to hum an eyelid conditioning. In A. H. Black \& W. F. Prokasy (Eds.), Classical Conditioning II. New York: Appleton-Century-Crofts, 1972, 119-147.

Prokasy, W. F. A two-phase model account of aversive classical conditioning performance in humans and rabbits. Learning \& Motivation, 1973, 4, 247-258.

Prokasy, W. F. Discriminated avoidance vs classical conditioning: A two-phase model analy'sis. Animal Learning \& Behavior, in press.

Prokasy, W. F., \& Whaley, F. L. The intertrial interval in classical conditioning. Journal of Experimental Psychology, 1961, 62, 560-564.

Prokasy, W. F. Williams, W. C., Lee, W. Y. M., \& Kumpfer, K. L. Two-phase model analysis of the effects of interstimulus interval and masking task in human aversive classical conditioning. Memory \& Cognition, 1974, 2, 206-210.

Rescorla, R. A. \& Solomon, R. L. Two-process learning theory: Relationships between Pavlovian conditioning and instrumental learning. Psychological Review, 1967, 74, 151-182.

Spence, K. W. Behavior theory and conditioning. New Haven: Yale University Press, 1956.

Spence, K. W. Behavior theory and learning. Englewood Cliffs, New Jersey: Prentice-Hall, 1960.

\section{NOTE}

1. Though not germane to present purposes, high $\theta$ values are evident. This is consistent with earlier results (Prokasy et al, 1974) to the effect that estimates of $\theta$ increase substantially with interstimulus intervals beyond .5 sec. 